\title{
"We smoke the same pipe": Religion and community home-based care for PLWH in rural Swaziland
}

Running title: We smoke the same pipe

Robin Root, $\mathrm{MPH}, \mathrm{PhD}^{1}$ [corresponding author]

Arnau Van Wyngaard, $\mathrm{PhD}^{2}$

Alan Whiteside, D Econ ${ }^{3}$

\section{Compliance}

This manuscript has not been published elsewhere, and it has not been submitted simultaneously for publication in another journal.

\section{Acknowledgements}

This study was funded with a grant from the Health Economics and HIV and AIDS Research Division (HEARD), University of KwaZulu-Natal. The Institutional Review Board of Baruch College, City University of New York approved the research protocol. Ethical research processes, including informed consent, were rigorously implemented. The authors declare no conflict of interest. The authors are grateful to the women and men of Shiselweni Home-based Care for their participation in the study; Casey Golomski for his invaluable contributions to the research process; and manuscript reviewers whose feedback contributed considerable value to the final product.

\begin{abstract}
We draw on a study of a church-run community home-based care organization in Swaziland to explore how individuals living with HIV perceived caregivers' impact on well-being. Our primary concern was to examine how religion, as a heuristic practice of Christian-based caregiving, was felt to be consequential in a direly underserved region. Part of a larger medical anthropological project, we conducted semi-structured interviews with 79 community home-based care clients, of whom half (53\%) said they would have died, some from suicide, without its services. We utilized a critical phenomenological approach to interpret semantic and latent themes, and explicated these themes within a 'healthworld' framework. Participants were resolute that
\end{abstract}

${ }^{1}$ Robin Root, MPH, PhD (corresponding author). Associate Professor, Department of Sociology \& Anthropology, Baruch College, City University of New York. Tel: 646.312.4481 (USA); Email: robin.root@baruch.cuny.edu

${ }^{2}$ Arnau van Wyngaard, PhD. Research Associate, Department of Science of Religion and Missiology, University of Pretoria, and CEO of Shiselweni Home-Based Care. Email: wyngaard@lando.so.za.

${ }^{3}$ Alan Whiteside, D Econ. Founder and former director of Health Economics and HIV/AIDS Research, University of KwaZulu-Natal, and CIGI Chair in Global Health Policy, Balsillie School of International Affairs. Email: awhiteside@ballsillieschool.ca 
caregivers be Christian, less for ideological positioning than for perceived ontological sameness and ascribed traits: "telling the truth" about treatment, confidentiality, and an ethos of unconditional love that restored clients' desire to live and adhere to treatment. Findings are intended to help theorize phenomenological meanings of care, morality, health, and sickness, and to interrogate authoritative biomedically based rationalities that underwrite most HIV-related global health policy.

Key words: Africa, home-based care, religion, HIV/AIDS, biomedicine, ART/ARV adherence, Africa

\section{Main text}

"Addressing another's pain is [...] about how a particular kind of relationship can be inhabited or enacted." - Talal Asad (2003:82)

"If these caregivers weren't Christian, I think I would be dead."

- 48-year old Swazi woman

\section{Introduction}

Oppositional rhetoric, competing funding, and institutional politics have long characterized academic and policy debates concerning religion and HIV/AIDS (Parker 2009; Burchardt, Hardon, and de Klerk 2009). Probing these epistemic frames, scholars have theorized the reciprocal mediation of religion and HIV/AIDS health policy/programming (Cochrane 2011; African Religious Health Assets Programme 2006), civil society mobilization and new modes of citizenship (Robins 2004), church roles (Prince, Denis, and van Dijk 2009), HIV-health practices (Trinitapoli and Regnerus 2006), and theologies of HIV/AIDS (Van Wyngaard 2013; Paterson 2009; Haddad 2009). In light of global health agendas designed increasingly to "task shift" HIV and other health services to community health workers (World Health Organization 2013), faith-based organizations, with their deep institutional and grassroots networks, may play an 'exceptional' role (Vitillo 2009) in an arguably 'exceptional' epidemic (Whiteside and Smith 2009). Religion has, in fact, long figured into community home-based care (CHBC) for people living with HIV/AIDS (PLWHA) (Rödlach 2011), yet scant research exists on the experiential and institutional mediation of religion and $\mathrm{CHBC}$, and the ways that this mediation may inform theoretical and applied inquiry in medical anthropology. Toward this 
end, we focus here on experiences of HIV/AIDS and religion instantiated through church run home-based HIV/AIDS care in Swaziland.

Swaziland is an ideal, albeit tragic, venue in which to address these questions: the population has long suffered the world's highest HIV and TB prevalence rates; the government's HIVIAIDS strategies rely substantially on CHBC services (Government of Swaziland [n.d.]); and the country's institutional landscape, from governance to medicine to kinship, is characterized by a plurality of Christian denominations. Conducted in 2009 and 2011, the aim of our two-phased study was to explore the significance of religiousbased CHBC to caregivers and clients of a rapidly expanding organization in rural southern Swaziland. In this article, we draw on the notion of 'healthworlds,' conceptualized as "an anthropologically rooted dimension of the lifeworld that thoroughly traverses it" (Cochrane 2011:12), to explicate CHBC practices that PLWHA felt improved their wellbeing and whether religion, as a heuristic practice of Christian-based, HIV-related caregiving and care-receiving, was felt to be consequential.

\section{Research Methods and Setting}

A small, landlocked country bordered by South Africa and Mozambique, Swaziland is known for its verdant, mountainous landscape and for being one of the few absolute monarchies in the world. It is also known for its intractable HIV/AIDS and TB epidemics. One in three adults (age 18-49) is HIV positive. Gender disparities across women's and men's lifetimes reflect entrenched vulnerabilities. Below age 25, female HIV infection rates $(26 \%)$ are five times that of males $(5 \%)$, and women's rates peak both earlier than men's (ages 30-34 vs. ages 35-39) and higher (54\% vs. 47\%) (Bicego, Nkambule, Peterson, Reed, and Donnell 2013:3). In recent years, however, some progress has been made. Between 2001-2011, new HIV infections dropped 37\%, and in 2012 Swaziland was one of only five countries in sub-Saharan Africa to achieve $>80 \%$ ART coverage (UNAIDS 2012). The government's current aim is to vigorously pursue a treatment-as-prevention strategy that hinges significantly on expanding CHBC.

A majority of Swazi (80\%) identify as Christian (PACANet 2008), though denominational affiliations may be fluid across an individual's life course. A ratio of one public health clinic to 6,451 Swazi versus one church per 200 contrasts a lack of ready access to formal health services with the institutional saturation of Swazi society by religious networks. Environmental vagaries, unproductive growth strategies, pervasive monarchial entitlements, and global commodities markets have wrought havoc on land 
use and food prices in direly injurious ways (Hickel 2012). Sixty-three percent of the population live below the national poverty line (World Bank 2014) and a majority (70\%) relies on subsistence agriculture (CIA 2013) for livelihood, albeit insufficiently. In 2011 the World Bank declared that Swaziland was "facing a social disaster of colossal dimensions" (2011).

\section{Case organization: Shiselweni Home-based Care}

Several scholars of religion have called for a focused theological response to HIV/AIDS (Bongmba and Cochrane 2007; de Gruchy 2011). Toward that end, a South African theologian (one of the authors) with three decades of missionary experience in Swaziland founded SHBC in 2006, ${ }^{4}$ when he proposed an initiative for Swazi parishioners to assist the unwell in their midst. With an initial 32 volunteers, by 2014 SHBC's caregiver base had grown to approximately 1,000 caregivers serving 3,500 clients in 39 rural communities across 1,095 square miles of southern Swaziland. Having implemented a rigorous data collection system in 2008, by 2013 SHBC demonstrated dramatic declines in client mortality (71.4\%) (Root, Van Wyngaard, Whiteside 2015). While causality between SHBC caregiver interventions and health outcomes is impossible to establish, the significance of religion to client experiences emerged as a worthwhile inquiry,

Briefly, four sociocultural and epidemiological processes help to explain SHBC's rapid uptake. First, high HIV morbidity and mortality meant that individuals who had long been caring for sick family members were keen to participate in SHBC training opportunities. Second, community leaders, including local chiefs, who had been unable to alleviate the suffering of their constituents observed SHBC's wide-scale impact and requested SHBC train its own volunteer corps. Third, Ubuntu, a philosophy of humanity indigenous to southern Africa, prescribes a sociality wherein "respect for an other [is] as a religious other" (Louw 1998, original italics). At its core, Ubuntu structures individual consciousness in communitarian terms, serving both as an "indigenous knowledge system" and a collective identity (Forster 2007). By articulating an ontological empathy of self as other, Ubuntu compels people to care for others in the belief that writ into society, into human consciousness, is a collective responsibility to care for others. SHBC's

\footnotetext{
${ }^{4}$ The Dutch Reformed Church (DRC) in South Africa was founded by Dutch missionaries in South Africa in the late 17th century. In 1945, the DRC established a missionary outpost in Swaziland that, over time, became indigenized as the Swaziland Reformed Church. Currently, the Swazi denomination has more than 2,000 members regularly meeting in homes and church buildings throughout Swaziland.
} 
Christian ethos hews to the Ubuntu worldview and is thus profoundly resonant among caregivers and clients alike.

SHBC's one-week trainings educate caregivers on conventional counseling practices concerning HIV prevention/testing, AIDS/TB treatment uptake/adherence, disclosure brokering, and basic first aid. To cultivate religious care practices, SHBC grounds its care ethos in a servant-leadership model based on the parable of Jesus who instructed his disciples to "wash one another's feet” (John 13:14). Extrapolated to a contemporary setting marked by extreme suffering, the parable is enacted in SHBC's 'graduation' ceremony, whereby the founding pastor bathes the feet of initiates to symbolize the dual physical and spiritual caregiving roles they will play in their communities.

\section{Methodology}

The concept of religious health assets as both direct and tangible as well as indirect and intangible (Olivier, Cochrane, and Schmid 2006:11) framed our initial aim to explore and explicate the significance of church run home-based HIV/AIDS care. For its epistemological focus on embodiment and (inter)subjectivity, and concern with how inequalities are implicated in patterns of sickness experiences (Good 1994), a critical phenomenological approach further guided the design of interview schedules and subsequent analysis. Our two-phase study was initiated in 2009, with a study of SHBC caregiver experiences (Root and Van Wyngaard 2010). In 2011, semi-structured interviews were conducted with 79 HIV-positive SHBC clients, which are the basis of this article. Experience was operationalized in terms of perceived wellbeing; urgent needs and help-seeking practices; perceptions of SHBC caregivers; disclosure experiences; HIV health practices; and the significance of caregivers' Christian affiliation and care practices. The semi-structured interview schedule was comprised of structured ("Would you say your health is better, about the same, or worse since the care supporter began visiting you?", "If better or worse, how so?") and unstructured questions (e.g., "What is the most important thing [care supporters] do for you?") formulated to explore PLWHA experiences of community home-based care.

Participants were notified of the study in advance by SHBC caregivers and informed consent was secured when the interview was conducted in person. Requisite criteria that the participant was HIV-positive status and a current SHBC client were confirmed before interviews commenced. Most interviews were audio-recorded, for which separate informed 
consent was secured. Hard copies of an English language version of the schedule were printed, brought to the research site, translated into siSwati by SHBC's Swazi chief operating officer, and reverse translated. With Swazi interpreters from SHBC, a principal investigator and a US Fulbright Scholar conducted the bulk of the interviews, which required about 30 minutes to administer and were conducted in private spaces in community settings: at churches, a chief's residence (umphakatsi), an orphan care point (gogo center), and a chief's administrative center (inkhundla). Translated responses were summarized on the interview form. Concurrency of data collection and analysis is characteristic of much qualitative research (Thorne 2000:68) and manifest in our study to the extent that a few questions were dropped and added as new meaningful probes emerged. Thus, the number of participants who responded to a few questions varied. The Institutional Review Board of Baruch College, City University of New York approved the research protocol.

\section{Study limitations}

The sampling frame for the study included all SHBC clients, and the sampling strategy was self-selection. There are inherent limitations to all non-probabilistic strategies that are important to consider when interpreting study findings. As a selfselected cohort, participants may have had particularly compelling SHBC experiences and therefore were more inclined to vocalize those experiences, thus biasing results towards common rather than divergent accounts. However, because participants were sampled from multiple SHBC-serviced communities, the potential for this bias was likely minimized. Second, participants might have been available for the study because they were in overall better health than non-participants who might have been too unwell to join in the study, thus biasing findings towards individuals who have benefited more than others from SHBC. Third, two-thirds of participants were women, a preponderance that may skew findings toward female experiences; however, because two-thirds (62\%) of all SHBC clients are female, the gender ratio in the study was expected. Last, by providing translation and paraphrasing participant responses, interpreters may have influenced content. Because SHBC caregivers are highly respected as uncommon guardians of confidentiality, their involvement in this regard likely was not limiting.

\section{Results and Analysis}

Integrating results reporting with analysis, as we undertake here, demonstrates the 
fundamentally interpretive endeavor that much medical anthropological research entails, especially of a phenomenological bent. We provide a descriptive analysis of structured responses in tandem with an applied thematic analysis of open-ended content, whereby analysis of "text [was] a proxy for experience" (Guest, MacQueen, Namey 2012). Close, iterative readings and manual coding of participants' reports generated 32 codes (Table 1) that were inductively abstracted to seven main categories (Table 2), which accords with the three to eight main categories characteristic of general inductive studies (Thomas 2006). Hermeneutic interpretation (Kinsella 2006) of study results was also informed by each author's longstanding engagement with Swaziland in some form. ${ }^{5}$

A primary thematic finding was that Christianity constituted a distinctive resource for SHBC caregiver impact on clients' subjective wellbeing. Semantic analysis of participant reports suggested that caregivers achieved this impact through three domains of HBC practices: they rendered conventional HIV/AIDS scripts both actionable and personally relevant, provided essential material and custodial assistance, and offered ongoing, realtime support that is generally glossed in clinical and health-oriented literature as 'psychosocial.' Latent thematic analysis generated insights on how Christianity mediated the impact of each domain in ways that participants' felt were integral to their wellbeing. We turn now to a thematic conceptualization of how religious mediation of bodies, relationships, and privations, instantiated between caregivers and clients, was believed to have this impact.

Table 1: Selected codes for religious mediation

\begin{tabular}{|l|}
\hline \hline \multicolumn{1}{|c|}{ Category codes } \\
\hline \hline Keeps confidentiality better \\
\hline "Tells the truth" about where to seek treatment \\
\hline Has a "unique heart" \\
\hline Instructs how to behave - moral disciplinary care \\
\hline "Trust" because both are Christian \\
\hline Caregiver power/love channeled from God \\
\hline Qualities to "adopt" from Christian caregivers (aspirational) \\
\hline
\end{tabular}

${ }^{5}$ RR has been studying social aspects of HIV/AIDS in Swaziland since 2005. AVW has been a missionary pastor in Swaziland for the past 30 years. AW was brought up in Swaziland and has been engaged in economic analysis and HIV research for over 30 years. In 2003, he was appointed by then UN Secretary-General Kofi Annan to the Commission for HIV/AIDS and Governance in Africa. 
Table 2: Thematic analysis: seven main categories

\begin{tabular}{|l|l|}
\hline \multicolumn{1}{|c|}{ Category title } & \multicolumn{1}{c|}{ Description } \\
\hline Category 1: Stigma reduction & $\begin{array}{l}\text { The role of HIV stigma and impact of stigma } \\
\text { reduction by care supporters. }\end{array}$ \\
\hline Category 2: Comprehensive health impact & $\begin{array}{l}\text { Caregivers provided material, psychosocial, } \\
\text { physical relief }\end{array}$ \\
\hline Category 3: Talk as intervention & $\begin{array}{l}\text { Dialogue with caregivers transformed the } \\
\text { meanings of being HIV positive and HIV health } \\
\text { practices }\end{array}$ \\
\hline $\begin{array}{l}\text { Category 4: 'Home-based' HIV-positive } \\
\text { experiences }\end{array}$ & $\begin{array}{l}\text { Impact of caregivers' modeling of 'love' on } \\
\text { family care practices and PLWHA experiences } \\
\text { 'home' }\end{array}$ \\
\hline Category 5: Self-care practices & $\begin{array}{l}\text { Cultivating PLWHA self-efficacy by enabling } \\
\text { real time HIV healthy practices }\end{array}$ \\
\hline Category 6: Caregiver limitations & Frustration with material constraints \\
\hline Category 7: Religious mediation & $\begin{array}{l}\text { Christianity as a distinctive comprehensive } \\
\text { resource for HIV/AIDS care }\end{array}$ \\
\hline
\end{tabular}

\section{Sample}

Approximately two-thirds (64.6\%) of the sample was women and the remainder (35.4\%) men. The average age was 44 years, and ranged from 17 to 75 . Half $(50.7 \%)$ were aged $25-44$, and one in four (22.8\%) was aged 55 or older. One-half $(54.4 \%)$ had attained some primary schooling. Virtually every participant experienced HIV positivity amidst extreme material scarcity. Forty-four percent reported that they were single/never married, though many cohabitated with a sexual partner. It is important to note that conventional demographic categories such as 'marital status' mask the complex marital, familial, and sexual realities beneath these rubrics that impact individuals' experiences of HIV/AIDS. One participant, for example, a 57-year old woman, described her status as 'single/unmarried' and 'separated.' The multi-phased marriage process in Swaziland that results in a woman's patrilocal move to the groom's homestead likely was never realized. We indexed her liminal marital status as single/unmarried.

\section{Embodying wellbeing}

An overwhelming majority (92\%) felt their health had improved since caregivers began visiting them. Across participant reports, caregivers' ascribed authority to normalize an HIV status was instrumental to caregivers' impact on participants' wellbeing. Caregivers understand PLWHA suffering, said one participant, and "encourage me to not kill myself as other HIV-positive people do." Suicide prevention, and alleviating the suffering associated with suicidal ideation, emerged as critical, life- 
saving interventions. About half (53\%) indicated that they would have died, a few from suicide, if caregivers had never come into their lives. For a 37-year old man, "better health' meant "I could live with HIV; I wouldn't kill myself." Creating safe spaces to express grief about an often frightening and isolating diagnosis, caregivers were sources of concrete health information and culturally relevant insight about how to build a new life in a severely resource constrained, high HIV stigma setting. Asked how she felt at the start of the interview, a 37-year old participant, her infant against her breast, said she was feeling "so happy today." However, "if the caregiver didn't come to my house [that first time], I was ready to commit suicide, because I know the disease that I have is incurable." The caregiver resuscitated her desire to live by explaining how "everyone is living with HIV. People are living, and they are going to live." It was felt by some participants that discontinuance of SHBC services would pose a serious challenge to their survival.

Christians as truth tellers: credible counsel and confidentiality

A large majority of participants (86\%) viewed caregivers as both 'health' and 'religious' people, a finding that likely reflects the authors' reductive, etic framing of health/sickness and religion as discrete, sui generis constructs. In their study of religion and health in Lesotho, researchers with the African Religious Health Assets Programme (ARHAP) likewise found what they conceptualized as a failure of western secular frames to achieve a "translation" between incommensurable epistemologies of religion/health: a failure, thus, to appreciate and incorporate "the reality" of persons whose healthworld arises from "socialized forms of knowledge linked to the full range of relevant action contexts that confront a human being in life (Cochrane 2011:12). ${ }^{6}$ Asked to describe the religious aspects of care, a 63-year old woman answered, "They greet me, pray, preach, and say continue ARVs." Equipped with a Bible in their first aid backpacks, SHBC caregivers often enacted some religious care practice, in most instances reading aloud from the Bible and praying for and with the client. Most participants (77\%) said their religious feelings had changed since a caregiver began visiting them, becoming more intense, which could manifest in more frequent church attendance and internalizing a sense of God's love. And though a minority (15\%) of participants said they themselves

${ }^{6}$ For an excellent history of ARHAP and the concept of healthworld, please see Holman (2015). 
did not identify as Christian, nearly every participant felt it was important that caregivers be Christian.

Paramount to SHBC's impact was participants' construction of Christian caregivers as vigilant guardians of confidentiality and attribution of credibility to caregivers' HIV/AIDS counseling. Explained a 43-year old man, "In our churches, there are HIV-positive people, so it is easier to preach the gospel of [HIV] testing if the caregiver is a Christian, because she's also a believer." This production of ontological sameness, a shared teleology towards wellbeing, infused participants' healthworld as "a way of knowing and acting in the world that is intrinsically and holistically redemptive" (Germond and Cochrane 2010:310). Caregivers' twinning of religious with treatment adherence counseling was fundamental to many participants' SHBC perceptions of how caregivers enhanced their wellbeing. A 32-year old woman felt "encouraged, because God helps me to not stop taking my pills." Caregivers' HIV-related communication was felt to be exceptionally clear, compassionate, and judgmental to the extent that caregivers' 'judged' clients worthy of God's love and therefore of ARVs.

Caregivers' authority on HIV health practices derived significantly from their religious authority: "Whatever they teach me," said one participant, "I believe it, especially when they say I should drink the tablets [ART] and that I must ask help from God to open the minds of doctors to give me the correct medicine." In a setting marked by competing, pluralistic claims on the source of sickness and healing modalities, many participants felt that Christian caregivers "tell the truth" about seeking HIV-related treatment at the clinic. Where other researchers have described "competing healthworlds" as sources of "collective wisdom" that individuals can draw upon (Fried, Harris, Eyles, and Moshabela 2015:631), participant reports in our study suggested these competing healthworlds had to be strenuously navigated, and that caregivers could be instrumental in this effort. More than one in four (27\%) participants said they had been "discouraged" from taking ART by friends, family members, or colleagues. Some were pressured to desist from ARV, told they were wrongly influenced by caregivers, and threatened with violence. In the face of marginalizing and stigmatizing pressures to desist from ARVs, participants' ascription of medical and moral credibility to caregiver counsel was therefore felt to be especially important to wellbeing.

\section{Christians don't have "a hard-hearted heart"}

Participants' overwhelming preference for Christian caregivers was explicable less in 
terms of religious orthodoxy than because they were constructed as people who give credible health counsel, protect confidentiality, and have the "heart" to endure the ongoing tribulations PLWHA face. "A Christian accepts you with the disease," said a 46year old woman, "[so that] person will understand my suffering." A 48-year old woman explained how they "help me in all ways, spiritually and physically. If these caregivers were not Christian, I think I would be dead." A caregiver's Christian identity is important, explained a 31-year old man, because "if a caregiver is a Christian, with the love of God, that person transfers the love of God to sick people." This material conveyance of Godly love was contrasted with non-Christians' lack of it: "If you are a Christian, you get the power to do all those [good] things from God. If you're not a Christian, you have a hardhearted heart." Likewise, a 53-year old male conferred upon caregivers a unique healing power that augmented ART. "We are getting help through the caregivers because of God's love," he said. "If God's love was not there, we would not have these caregivers."

Through their embodied and enacted 'love,' sourced from a Christian ethos, caregivers were often authoritatively positioned to thwart this life imperiling process at a site that clinic personnel could neither reach nor readily influence but which was all important: the home. Golomski has described the sociocentric and socioreligious modus operandi of "love" in Swazi society: "Love is effected by, originates from, and is equivalent to God. Love facilitates sociality, be it between families, spouses, partners, neighbors, or members of the same church or organizations" (2011). Having a Christian 'heart' thus emerged as a culturally potent, indigenous competency that enabled caregivers to tend to clients' affective and bodily needs amidst entrenched HIV stigma and dire material constraints. Demonstrated in the presence of family members, love as an intangible care practice was often as consequential, given that the family (umuti) in Swazi society “is the primary agency for realizing and assuring [a person's] birthright to support and sustenance [...] and assistance and protection... when he is ill or infirm" (Ngubane 1983:103). Without umuti, whether as a result of HIV stigma or because an individual was too unwell to contribute to homestead livelihood, personhood and wellbeing may be imperiled.

HIV stigma and the loss of legitimate personhood suffered by many HIV positive persons meant that restoring personhood was the first step in achieving HIV-healthy practices. The health impact of conjoining treatment counseling with religious care practices was evident in the report of a 48-year old widow who explained how "my caregiver shares the word of God with me... and encourages me to go on with my 
medications." Treatment adherence was construed and experienced by participants as a religious obligation as well as a 'health practice.' A 57-year old woman described how religious intensification, expressed through prayer, facilitated ART adherence: "God, since you know that I am now HIV positive, help me to be perfect in taking my medications." Feeling "more religious" after a caregiver entered her life, a 32-year old woman said, "I've raised myself a lot...I am encouraged because God helps me to not stop taking pills." To be deserving of love was to be deserving of life and therefore of medications.

A paramount feature of many participants' lives prior to caregivers' arrival was social isolation. However, in a setting where reciprocity is a key social and economic dynamic, social isolation was rarely only social. A 43-year old woman described caregivers' unique and indispensable roles: "I think if there were no caregivers, I would die; I see the help I get from them. Without them, I would have to go to the police station and say, 'please take care of me, even if you must put me in prison as a prisoner, because I have no place to stay." Asked what would happen should the caregiver no longer visit, several participants said it would be "painful." A 42-year old woman explained how caregivers' mobilization of religion in the project of self-care effectively "translated" for the authors how (our) parsing of religion and health risked missing the precise means by which caregivers achieved their impact. Without SHBC caregivers, she explained, she would continue going to the clinic, "but I wouldn't keep myself well. The caregiver helps and encourages me [through] Christianity." The locus of health, and therefore of (eticallyframed) health practices, thus originated not in the singular individual but in relationships that shared the same goal of comprehensive wellbeing.

\section{Moral authority: reducing stigma and shaping HIV health practices}

More than one in four (27.9\%) participants sought HIV testing and nearly a third (31\%) initiated ART after a caregiver began counseling them. Asked why it mattered whether caregivers were Christian, a 53-year old woman answered, "Because we smoke the same pipe." This cultural idiom captured the shared quality, a kind of ontological sameness that bound the caregiver with the participant in ways that deepened the impact of HIV/AIDS counseling. This "subject-subject response to illness or dysfunction," write Germond and Cochrane, is "a sine qua non," refracted in our study through church run $\mathrm{HBC}$ that demonstrated the seamlessness of religious with health phenomena and epitomized the "coherent, organized patterns of interpretation that guide" health 
practices (2010:320). A 37-year old woman explained that "there is nothing to adopt [learn] from a non-Christian caregiver," and a Christian caregiver counsels that "no matter the disease, you must accept yourself as you are. When you take [ARVs], you must also accept Lord Jesus Christ as your Savior." To accept Jesus was to simultaneously accept an HIV-positive status and one's HIV-positive self; together, this trinity of Jesus, status, and self restored to many participants a sense of personhood worthy of life and thus of ARVs.

In contrast with clinic staff, it was often felt that through home visitation SHBC caregivers accrued the necessary insights about an individual's life to prevent suicidal ideation on an ongoing basis, in real-time. Christian care practices figured substantially into this project. For a 56-year old woman, a caregiver would ideally be Christian because HIV-positive individuals may feel discriminated against to the point where they may wish to end their lives. A Christian caregiver instructs that it is not right in front of God to kill yourself: “'Just repent,' the caregiver will say, 'God is there."' The despair that caregivers dissipated in this manner could profoundly influence participants' and their families' lives. A 42-year old woman likewise felt it was important that a caregiver be Christian, because "I want to raise my kids, and the caregiver encourages me to refrain from killing myself as other HIV positive people do." Caregivers convinced her that God loved her and suicide would be a sin.

Religious care practices were disciplinary in other ways believed to enhance wellbeing. A 48-year old woman whose husband and son had died felt that caregivers' religious moralizing was an important and desirable care practice. The caregiver "will help me when I'm going astray," for example if she sought traditional healing or perhaps a sexual partner. Her caregiver chided her, 'No, a child of God doesn't do this." A $42-$ year old woman likewise said that she and her caregiver discussed adopting new behaviors. Asked what behaviors, she explained, "A person on ARVs must be a Christian and must not roam around, because you are HIV positive. You must change your behavior because God likes people who respect themselves." Such moralizing tones would discomfit many 'western' health professionals for whom secularity is equivalent with science, and for whom that equivalency is essential to effective health programming. However, in our study, HIV health practices inhered in 'moral' adherence in such a way that each domain, the biomedical and the religious, exercised respective disciplinary imperatives that participants felt helped them.

Religious moralism in our study was experienced thus less as judgmental dictates 
than a form of desirable "moral formation" (ARHAP 2006:78) an intangible asset manifest as a shared wisdom that restored participants' sense of "moral agency" (ARHAP 2006:75). Repentance, for example, was often experienced among our participants as a portal to legitimate personhood and social incorporation that trumped others' stigmatizing judgment: "If you have the disease, the word of God encourages you, because God still loves you," explained a 47-year old woman. Christian SHBC discourses enabled an ontological sameness not only between caregiver and client, but between the HIV-positive and HIV-negative person as well. Asked how it felt to be encouraged by his caregiver to repent, a participant said it made him feel "very happy - I feel I am just the same, like any other person; there is no stigma." In his mind, "I just forgave myself, and said, 'no, I am just the same as others'." The notion that repentance could be lifesaving is especially noteworthy to a secular audience, given its 'outside' connotations as a conservative discourse that overwhelmingly blames and shames. In contrast, participants described Christian care scripts that sourced an HIV-positive personhood infused with self-worth using moralizing language that discomfit conventional health researchers, in part because such moralizing has, at times, had nefarious effects, especially with respect to fueling HIV stigma. However, our study findings corroborate ARHAP studies in Zambia and Lesotho that likewise found homebased care groups "to do well" in moral domains of study participants (ARHAP 2006:95).

\section{Discussion}

Anthropological discourses of religion vis-à-vis HIV/AIDS have been, at times, curiously dismissive of its complex semiotics and institutional significance, assuming instead political/polemical positions that flatten experiences of risk, gender, and sickness across cultural milieux (e.g., Schoepf 1995; Susser 2009). To be sure, religious responses have often undermined HIVIAIDS interventions with a "blame and shame" attitude (Campbell, Skovdal, and Gibbs 2011) that reifies "sexual morality... at the expense of other pressing issues" (Bongmba and Cochrane 2007:3). An ethnographic literature has emerged over the past decade, however, that theorizes these dynamics in ways resonant of anthropology's longstanding focus on religious collectivities, beliefs, and practices, and that integrates critical readings of biomedicine, neoliberalism, and globalization (Dilger, Burchardt, and van Dijk 2010). Studies of new communal formations and national HIV/AIDS policies in Uganda (Gusman 2009), ontological insecurities and "strategies of action" among HIV-positive women in South Africa (Burchardt 2010), and the transnational 
production of confessional technologies and "therapeutic evangelism" in Burkina Faso (Nguyen 2009) reflect this emerging ethnographic exegesis of the frictions that inhere in globalizing flows of capital, people, disease, and discourses.

Our study was designed to explore PLWHA experiences of church run home-based care in rural Swaziland. Drawing on phenomenological approaches in medical anthropology that examine "how...distress is experienced and expressed through the body in everyday life" (Becker 2004:126), we queried how it feels to HIV-positive individuals to participate in church run HBC in a high vulnerability, high HIV stigma setting. Embodiment was a productive heuristic because it "poses additional questions about religious experience" (Csordas 1990:40). The notion that some religious discourses may have "'better words' [for] questions of corporeality and finitude, person and individuality" (Germond and Cochrane 1010:319) than biomedicine alone was evident in participants' descriptions of caregivers' counsel as something more than mere health counseling: it was life envisioning. SHBC impact was thus largely attributable to the ways that shared Christian ethos, identities, and practices were described as restoring a sense of legitimate personhood to HIV-positive individuals. This legitimate self was empowered to act upon the(ir) body, specifically by taking up caregivers' counseling to seek testing, adhere to treatment, and, as appropriate, disclose an HIVpositive status.

The concept of religious health assets $(\mathrm{RHA})$ and healthworlds was central to explicating the social production and significance of religious-based HBC in participants' lives. Intangible RHA resided in SHBC's cultural capital, both its tangible (human) resources - caregivers and compassionate care - and the discursive and non-discursive ways in which they interpolated biomedical with religious-based care practices in ways that informed new HIV subjectivities (Burchardt, Hardon, de Klerk 2009). Similarly, ARHAP studies in Zambia and Lesotho found that "spiritual encouragement [was] perceived by far to be the strongest contribution of religion to health and wellbeing [and included] hope, faith, prayer, and trust and builds resilience and inner strength to deal with the health crisis in which people find themselves" (Appreciating Assets ARHAP 2006:126). The second most important contribution to health and wellbeing in the ARHAP study was "compassionate care," a feature that was foremost in our study as well, and framed (etically) in religious terms.

In many ways, SHBC functioned as a "regulator of hope" (Masquillier, Wouters, Mortelmans, and le Roux Booysen 2014:1) in a profoundly potent configuration of 
participants' lifeworlds - the home. It was 'here' that caregivers strengthened treatment uptake and adherence, and in so doing demonstrated a specific teleology whereby, according to Germond and Cochrane, the "healthworld is linked to agency governed by an interest in restoring, maintaining or increasing health; it is the framework that directs health-seeking behaviour" (2010:310). As households are "conventional sites for the social reproduction of Swazi persons" (Golomski 2011), home risks becoming, through abandonment and alienation of PLWHA, of their exclusion and devaluation, the primary site wherein the social destruction of Swazi personhood may also be experienced; this risk is arguably why home-based care is so consequential to PLWHA wellbeing. SHBC operated 'here,' at the pulse of experiences of self/other and sickness/wellness, in participants' lifeworlds. In her classic ethnographic of Swaziland, Kuper described the organizing principle of Swazi personhood, writing that a "[Swazi] person is a meeting point of identities - the identity of siblings, the identity of lineage, the identity of the age group" (1986[1963]:59). Personhood derives, as well, from an individual's ability to fulfill affective, material, and ritual obligations to family, living and deceased (Golomski 2013:39). With improved health came restored physical strength and the capacity to contribute to household wellbeing, a sine qua non for legitimate personhood.

The potent health impact attributed to SHBC caregivers can be explained, thus, by the ways in which moral experience is "emergent in everyday life if, and perhaps only if, it is supported by cultural concepts of the person that make people 'present' to each other in particular ways" (Parish 2014:33). At the heart of caregivers' and participants' recovery enterprise was a specific "relationality" (Cochrane 2011:9). By speaking with and touching the client ("bathing the hands and feet of Christ"), these relational, embodied, metaphoric encounters emerged as the locus/nexus of new meanings tied to empathy, sociality, ontology, sickness, and resilience. Theorizing the body as the nexus and locus of emergent meanings of HIV/AIDS and religion contrasts with secular HIV messaging that, grounded in a particular rationality, may be less resonant.

The metaphor of a Christian client and a Christian caregiver smoking "the same pipe" suggested an additional reading of the interpolation between religion and health. According to Cochrane, drawing on the ARHAP Lesotho study, the researchers' etic "'block of meaning"' (the divisibility of health and religion) was subverted by the authoritative, emic block: the indivisibility of self and others/ancestors/natural world, of health and religion in sickness, and the intrinsic indispensability of relationality to healing and well-being (2011:9-10). The benefits of these practices are attributable a "subject- 
subject response to illness" (Germond and Cochrane 2010:320), predicated on the availability of reliable and affordable treatment, and specific forms of communicative action entailed in religious-based home-based care HIV/AIDS counseling.

Caregivers embodied enactment of this relationality using a specific religious discourse, doctrine, and disposition in the home transformed the meanings and experiences not only of HIV subjectivities but of religious morality: to be moral was to care for HIV-positive persons, and to care for PLWHA was a moral as well as healthsupporting practice. Moral experience, writes Parish, is generated in the "space between persons" (2014:33). In this study, that space was constituted by relationships between caregivers and clients through HIV care practices with substantial religious valence. Csordas' theorizing of "care as essential to the moral domain" (2014:139) provides one reading of these insights: religious talk, HIV-health practices, and restored strength constituted a moral experience for most participants. To adhere to treatment (health practice) was also a religious imperative that, if heeded, helped to restore a moral personhood.

Church-run CHBC functioned thus as a specific horizon of action that, like the ARHAP study in Lesotho, pointed to specific "fundamental features of those dimensions of human experience we [biomedically-oriented health professionals] label religion and health, though without any implied dualism" (Cochrane 2011:12). Whereas HIV stigma, expressed and felt through pejorative words, physical separation, and marginalizing practices, violently disarticulated the moral person from the HIV-infected body, Christian-derived care scripts and practices collapsed this dualism in transformative ways, showing how embodiment "really does advance our understanding of a particular practice [and of] how practices are related among themselves" (Csordas 1990:28). The transformative, mutually reinforcing practices in this instance may be understood as two secularly constructed epistemic frames, religious and health-related.

\section{Conclusion}

Our aim in this manuscript has been to demonstrate how experiences of religiousbased home-based care must be understood in the context of cultural notions of personhood, relationships, and well-being, but also of unrelenting poverty, entrenched gender inequalities, and pervasive HIV stigma (Shamos, Hartwig, and Zindela 2009). In this setting, SHBC caregivers were described as fonts of unconditional love, limited 
material support, vital HIV/AIDS education, and anti-HIV stigma sentiments whose discourse was discursively Christian. By sourcing new forms of moral personhood that legitimated PLWHA in the eyes of HIV-positive clients themselves as well as family members, these discourses and associated care practices constituted a religious subjectivity that empowered many participants to access health services in ways they previously had not. The immanence of religion and biomedicine to HIV-positive experiences in these examples, and of biomedicine to religion, showed up some of the limitations of western, secular behavior change interventions that fail to appeal to, or to heal, the broken and exhausted hearts and bodies in empirical, culturally relevant, and health-enhancing ways.

In light of the global health politics that have long surrounded religion and HIV/AIDS at the policy/program level, a phenomenological approach framed within the explanatory concept of a 'healthworld,' demonstrated the critically important ways that religious discourses restored, invigorated, and advanced the perceived wellbeing of many participants. 'Better health' was experienced as a dynamic cultural and phenomenological enterprise. Fusing the sick self with a discursive belief in Jesus' 'unconditional love,' caregivers, by their physical presence in participants' lives, embodied SHBC's ethos to be "the hands and feet of Christ" and, as such, articulated a new personhood for their clients, one worthy of a religious-framed love and therefore of ART. We theorized this embodied mediation in part to nuance the zero-sum analysis of religion and science that has often dominated global health debates (when it is discussed at all); we did this by describing the embodied synergies of bio-scientific and socio-religious discourses in people's lives.

The concept of the healthworld is not devoid of structural concerns, such as lack of access to and availability of reliable treatment. Rather, in positing the notion that illness and wellbeing are socially constituted phenomena, the concept of healthworlds foregrounds for researchers' a cognizance of how ideal care pathways must integrate the representations of illness/religion of its intended beneficiaries, and vice versa, as well as why such pathways might be interrupted (Fried, Harris, Eyles, and Moshabela 2015:629). Similar to Ironson et al.'s (2002) finding of enhanced health among PLWHA who demonstrated high religiosity and spirituality, the religious and biomedical operated among our participants not as two mutually exclusive epistemologies; rather, they synergistically enabled restoration of a self worth living through sustained HIV care practices. This distinction, in fact, between a religious-mediated self deserving of 
biomedical treatment points up the ill-fitting etic framing of these experiences as separate, whereas here we found they are intrinsically, mutually constituted.

Clearly, further comparative research is needed to examine the experiences, operations, and impact of various religious and non-religious health entities in their mediation of health, self, and sociality. Such a project would both advance medical phenomenological studies of moral experience, sickness/health, self/sociality as well as inform applied understandings of new modes of citizenship and social capital in settings of worsening vulnerabilities. Echoing oft-stated recommendations for strengthening community health services in Swaziland (Escott and Walley 2005) and elsewhere, properly scaled linkages between $\mathrm{CHBC}$ and other health services are both lacking and essential; these are dire deficiencies given concerns over further burdening women with task-shifting and if $\mathrm{CHBC}$ is to be a centerpiece of global and national health agendas. A more thoroughgoing understanding of these conceptual, institutional, and experiential axes is essential not only for theorizing anthropological epistemologies of religion/health and the ontological significance of CHBC for PLWHA, but to conserving the vital and vulnerable human capital that caregivers constitute throughout Africa.

\section{References}

Asad, T.

2003 Formations of the Secular: Christianity, Islam, Modernity. Stanford, CA: Stanford University Press.

African Religious Health Assets Programme

2006 Appreciating Assets: The Contribution of Religion to Universal Access in Africa. Report for the World Health Organization. Cape Town, South Africa.

Agadjanian, V. and S. Sen

2007 Promises and Challenges of Faith-Based AIDS Care and Support in Mozambique. American Journal of Public Health 97(2):362-366.

Becker, G.

2004 Phenomenology of health and illness. In Encyclopedia of Medical Anthropology. C. Ember and M. Ember, eds. Pp. 125-136. New York: Kluwer Academic/Plenum Publishers.

Bicego G., R. Nkambule, I. Peterson, J. Reed, D. Donnell, H. Ginindza, et al. 2013 Recent Patterns in Population-Based HIV Prevalence in Swaziland. PLoS ONE 8(10):e77101. doi:10.1371/journal.pone.0077101. 
Bongmba, E. and J. Cochrane

2007 Editorial: Theology, HIV/AIDS and Public Policy in Africa. Special edition. Religion and Theology 14(1,2):1-5.

Burchardt, M., A. Hardon, and J. de Klerk

2009 Faith Matters: Religion and Biomedical Treatment for HIV/AIDS in Sub-Saharan Africa. Diemen, the Netherlands: AMB Publishers.

Burchardt, M.

2010 "Life in Brackets": Biographical uncertainties of HIV-positive women in South Africa. Forum: Qualitative Social Research 11(1):1-23.

Campbell, C.

2003 Letting Them Die: Why HIV/AIDS Prevention Programmes Fail. Indiana University Press, Oxford.

Campbell, C., M. Skovdal, and A. Gibbs

2011 Creating social spaces to tackle AIDS-related stigma: reviewing the role of church groups in Sub- Saharan Africa. AIDS and Behavior 15(6):1204-1219.

Campbell, C. and C. Foulis

2004 Creating contexts for effective home-based care of people living with HIV/AIDS.

Curationis 27(3):5-14.

CIA

2013 The World Factbook: Swaziland. Electronic document, www.cia.gov/library/publications/the-world-factbook/geos/wz.html, accessed August 17, 2014.

Csordas, $\mathrm{T}$.

1990 Embodiment as a paradigm for anthropology. Ethos 18(1):5-47.

Csordas, $\mathrm{T}$.

2014 Afterword: Moral experience in anthropology. Ethos 42(1):139-152.

de Gruchy, S.

2011 Systematic theological reflection on HIV and AIDS: mapping the terrain. In Religion and HIV and AIDS: Charting the terrain. B. Haddad, ed. Pp. 170-197.

Pietermaritzburg, South Africa: Cluster Publications.

Desjarlais, R. and C. Throop

2011 Phenomenological approaches in anthropology. Annual Review of Anthropology 40:87-102.

Dilger, H., M. Buchardt, and R. van Dijk

2010 Introduction - The redemptive moment: HIV treatments and the production of new religious spaces. Special section on religion and antiretroviral therapy. African Journal of AIDS Research 9(4):373-383. 
Escott, S. and J. Walley

2005 Listening to those on the frontline: Lessons for community-based tuberculosis programmes from a qualitative study in Swaziland. Social Science \& Medicine 61(8):1701-1710.

Forster, D.

2007 Identity in relationship: the ethics of Ubuntu as an answer to the impasse of individual consciousness. In The Impact of Knowledge Systems on Human Development in Africa, ed. C. Du Toit, ed. Pp. 245-289. Pretoria, South Africa: Research Institute for Religion and Theology, University of South Africa.

Fried, J., Harris, B., Eyles, J., and M. Moshabela 2015 Acceptable Care? Illness Constructions, Healthworlds, and Accessible Chronic Treatment in South Africa. Qualitative Health Research 25(5): 622-635.

Golomski, C.

2013 Right Passages: Work and Ritual in Swaziland's Age of HIVIAIDS. Ph.D. dissertation, Department of Anthropology, Brandeis University.

2011 The Pragmatics and Politics of Sexual Orientation in Africanist Ethnography of HIVAIDS and Religion ${ }^{1}$. Department of Anthropology, Brandeis University. Paper for the "Sexuality, AIDS and Religion: Transnational Dynamics in Africa" conference, School of Anthropology, Oxford University. 29 September.

Good, B.

1994 Medicine, rationality and experience. Cambridge: Cambridge University Press.

Government of Swaziland

[n.d.]. The national multi-sectoral strategic framework for HIV/AIDS: 2009- 2014. Electronic document, www.ilo.org/wcmsp5/groups/public/---ed_protect/---protrav/---

ilo_aids/documents/legaldocument/wcms_174723.pdf, accessed January 11, 2015.

Guest, G., K. MacQueen, and E. Namey

2012 Applied Thematic Analysis. Thousand Oaks, CA: Sage Publications.

Gusman, A.

2009 HIVIAIDS, Pentecostal churches, and the "Joseph Generation" in Uganda. Africa Today 56(1):67-86.

Haddad, B.

2009 Poverty, gendered cultural sexual practices and HIV: Ethical and theological implications. Journal of Constructive Theology 15(2):5-22.

Hickel, J.

2012 Neoliberal plague: The political economy of HIV transmission in Swaziland. Journal of Southern African Studies 38(3):513-529.

Holman, S.

2015 Beholden: Religion, Global Health, and Human Rights. New York, NY: Oxford University Press. 
Ironson, G., G. Solomon, E. Balbin, M. Kumar, D. Larson, and T. Woods

2002 Ironson-Woods spirituality and religiousness index is associated with long survival, health behaviors, less distress, and lower cortisol in people living with HIV/AIDS: the IWORSHIP scale, its validity and reliability. Annals of Behavioral Medicine 24(1):3448.

Kinsella, E.

2006 Hermeneutics and critical hermeneutics: Exploring possibilities within the art of interpretation. Forum: Qualitative Social Research 7(3): Article 19. Electronic document, www.qualitative-research.net/index.php/fqs/article/view/145/319, accessed January 11, 2015.

Kuper, $\mathrm{H}$.

1986 [1963] The Swazi: A South African Kingdom. New York: Holt, Rinehart, and Winston.

Louw, D.

1998 Ubuntu: An African Assessment of the Religious Other, the Paideia Archive. Paper presented at the Twentieth World Congress of Philosophy, Boston, Massachusetts. August. Electronic document, www.bu.edu/wcp/Papers/Afri/AfriLouw.htm, accessed September 12, 2014.

Masquillier, C., E. Wouters, D. Mortelmans, and F. le Roux Booysen

2014 Families as catalysts for peer adherence support in enhancing hope for people living with HIV/AIDS in South Africa. Journal of the International AIDS Society 17(1):18802.

Ngubane, $\mathrm{H}$.

1983 The Swazi Homestead. In F.D.Vletter, ed. The Swazi Rural Homestead. Chapter 3. Kwaluseni, Swaziland: University of Swaziland Social Science Research Unit. No pages.

Nguyen, V.K.

2009 Therapeutic evangelism: confessional technologies, antiretrovirals and bio-spiritual transformation in the fight against AIDS in West Africa. In F. Becker and PW Geissler, eds. AIDS and Religious Practice in Africa. Pp. 359-378. Leiden, The Netherlands: Brill.

Olivier, J., T. Cochrane, and L. Schmid 2006 ARHAP Literature Review: Working in a Bounded Field of Unknowing. Cape Town: African Religious Health Assets Programme. Electronic document, http://jiflc.com/wpcontent/uploads/2014/05/arhaplitreview_oct2006.pdf, accessed January 11, 2015.

Pan African Christian AIDS Network (PACANet)

2008 Situational Analysis: Swaziland Report. Electronic document, www.pacanet.net/ index.php?option=com_docman\&task=cat_view\&gid=23\&ltemid=40, accessed January 11, 2015.

Paterson, $\mathrm{G}$.

2009 HIV prevention: A global theological conversation. Geneva: Ecumenical Advocacy Alliance. 
Parish, S.

2014 Between persons: How concepts of the person make moral experience possible. Ethos 42(1):31-50.

Parker, R.

2009 Civil society, political mobilization, and the impact of HIV scale-up on health systems in Brazil. Journal of Acquired Immune Deficiency Syndrome 52(S1):S49-S51.

Pfeiffer, J. and M. Nichter

2008 What can critical medical anthropology contribute to global health?: A health systems perspective. Medical Anthropology Quarterly 22(4): 410-415.

Prince, R., P. Denis, and R. van Dijk

2009 Introduction to Special Issue: Engaging Christianities: Negotiating HIV/AIDS, Health, and Social Relations in East and Southern Africa. Africa Today 56(1):v-xviii.

Robins, S.

2004 'Long live Zackie, Long live': AIDS activism, science and citizenship after apartheid. Journal of Southern African Studies 30(3):651-672.

Rödlach, A.

2011 Religious institutions and volunteering to provide care to people living with HIV and AIDS in Zimbabwe. Religion, Health, and Healing: An Interdisciplinary Inquiry. Journal of Religion and Society Supplement Series 7:198-215.

Root, R. and A. Whiteside

2013 A qualitative study of community home-based care and antiretroviral adherence in Swaziland. Journal of the International AIDS Society 16.

Root, R. and A. Van Wyngaard

2010 Free Love: A Case Study of Church-run Home-based Caregivers in a High Vulnerability Setting. Global Public Health: An International Journal for Research, Policy and Practice 6(S2):S174-91.

Root, R., A. Van Wyngaard, and A. Whiteside.

2015 Reckoning HIV/AIDS care: A longitudinal study of community home-based caregivers and clients in Swaziland. African Journal of AIDS Research, doi: 10.2989/

16085906.2015.1059864.

Schoepf, B.G.

1995 Culture, Sex Research and AIDS Prevention in Africa. In Culture and Sexual Risk:

Anthropological perspectives on AIDS. H. ten Brummelhuis and G. Herdt, eds.

Langhorne, PA: Gordon and Breach. Pp. 29-52.

Shamos, S., K. Hartwig, and N. Zindela

2009 Men's and women's experiences with HIV and stigma in Swaziland. Qualitative Health Research 19(2):1678-1689.

Susser, I.

2009 AIDS, Sex, and Culture: Global Politics and Survival in Southern Africa. WileyBlackwell Publishers: Hoboken, NJ. 
Thomas, D.

2006 A general inductive approach for qualitative analysis. American Journal of Evaluation 27(2):237-246.

Thorne, S.

2000 Data analysis in qualitative research. Evidence-Based Nursing 3:68-70.

Trinitapoli, J. and M. Regnerus

2006 Religion and HIV-risk behaviors among married men: initial results from a study in rural sub-Saharan Africa. Journal for the Scientific Study of Religion 45(4):505-528.

UNAIDS

2012 UNAIDS World AIDS Day Report. Electronic document, http://www.unaids.org/sites/default/files/en/media/unaids/contentassets/documents/ep idemiology/2012/gr2012/JC2434_WorldAIDSday_results_en.pdf, accessed January $11,2015$.

van Dijk, R.

2009 Gloves in times of AIDS: Pentecostalism, hair and social distancing in Botswana. In F. Becker and P.W. Geissler, eds. AIDS and Religious Practice in Africa. Pp. 283-308. Leiden, The Netherlands: Brill.

Van Wyngaard, A.

2013 Addressing the spiritual needs of people infected with and affected by HIV and AIDS in Swaziland. Journal of Social Work in End-of-Life and Palliative Care 9(2/3):226240.

Vitillo, R.

2009 Faith-based responses to the global HIV pandemic: exceptional engagement in a major public health emergency. Journal of Personalized Medicine 7(2):77-84.

Whiteside, A. and J. Smith

2009 Exceptional epidemics: AIDS still deserves a global response. Commentary. Globalization and Health 5:15. doi:10.1186/1744-8603-5-15

World Bank

2014 Swaziland. Electronic document, http://data.worldbank.org/country/swaziland, accessed August 17, 2014.

World Bank

2011 Swaziland country brief. Electronic document, http://go.worldbank.org/5XUKCEC850, accessed October 14, 2011.

World Health Organization

2013 Consolidated guidelines on the use of antiretroviral drugs for treating and preventing HIV infection: recommendations for a public health approach. June. Electronic document, www.who.int/hiv/pub/guidelines/arv2013/en/, accessed January 11, 2015. 